Beyond the tip of the iceberg : Adolescent weight development of women and men with features of binge eating disorder

\author{
Mustelin, Linda
}

2018-08

Mustelin , L , Kaprio , J \& Keski-Rahkonen , A 2018 , ' Beyond the tip of the iceberg :

Adolescent weight development of women and men with features of binge eating disorder ' , Eating behaviors, vol. 30 , pp. 83-87 . https://doi.org/10.1016/j.eatbeh.2018.06.004

http://hdl.handle.net/10138/316304

https://doi.org/10.1016/j.eatbeh.2018.06.004

cc_by_nc_nd

acceptedVersion

Downloaded from Helda, University of Helsinki institutional repository.

This is an electronic reprint of the original article.

This reprint may differ from the original in pagination and typographic detail.

Please cite the original version. 


\section{BEYOND THE TIP OF THE ICEBERG: WEIGHT TRAJECTORIES OF WOMEN AND MEN WITH FEATURES OF BINGE EATING DISORDER}

Linda Mustelin, MD, PhD, MPH, Jaakko Kaprio MD, PhD, Anna Keski-Rahkonen, MD, $\mathrm{PhD}, \mathrm{MPH}$

Department of Public Health, University of Helsinki, Finland, Institute for Molecular Medicine Finland FIMM, University of Helsinki, Helsinki, Finland

Corresponding author:

Dr. Linda Mustelin, Department of Public Health, University of Helsinki, PO Box 20,

Tukholmankatu 2B, 5th floor, 00014 University of Helsinki, Finland

linda.mustelin@helsinki.fi 


\begin{abstract}
Objective: Binge eating disorder (BED) represents the tip of the iceberg of disordered eating behaviors related to overweight and obesity. Little is known about how subclinical symptoms reminiscent of BED relate to weight development in adolescence and young adulthood.
\end{abstract}

Method: Women ( $n=2825)$ and men $(n=2423)$ from the community-based longitudinal FinnTwin16 cohort participated. Seven eating-related cognitions and behaviors similar to the defining features of BED were extracted from the Eating Disorder Inventory-2 and were assessed at a mean age of 24 . We used linear mixed models to assess the association of features of BED with BMI trajectories across five waves of data collection (mean ages 16, 17, 18,24 , and 34).

Results: The number of features of BED at wave 4 (age 24) was significantly associated with BMI from age 16 years onwards. Women and men with more features of BED continued to gain more weight throughout adolescence and early adulthood.

Conclusions: Features of BED in young adulthood were preceded by steeper weight trajectories in adolescence. A higher number of features were consistently associated with higher BMI and more weight gain.

Key words: eating behavior, binge eating disorder, body mass index, weight gain, adolescents, epidemiology, cohort studies, longitudinal studies 


\section{INTRODUCTION}

The spectrum of illnesses and disorders in the community resembles an iceberg: the visible part of the iceberg represents the clinically apparent cases of disease, whereas the submerged part represents the latent or subclinical cases that form the bulk of the phenomenon $(1,2)$. With a population prevalence of $<1 \%-3.5 \%$ (3-7) BED represents the tip of the iceberg of disinhibited eating behaviors. It is associated with obesity (8) and often preceded by unfavorable weight trajectories (6). While clinical BED is relatively rare, subclinical features of BED are widespread in the population (9). Yet, such features are often overlooked because their clinical significance remains unclear.

The core behavioral features of BED, binge eating and loss of control eating, predict weight gain and overweight among children and adolescents (10-12). These symptoms appear longstanding (13-15). Far less is known about how other subclinical BED symptoms relate to weight development in adolescence. The focus of previous research has been on individual behaviors. Yet, little is known about the cumulative effect of several simultaneous behaviors and cognitions.

We have previously reported an association between features of BED and BMI in young adults (9). In the present study we studied whether these features were associated with weight gain in adolescence. Specifically, we compared weight trajectories in adolescence between subjects reporting different numbers of BED-related features as young adults.

\section{SUBJECTS AND METHODS}

\section{FINNTWIN16 BIRTH COHORTS}

This nationwide longitudinal cohort study of health behaviors in twins and their families identified twin births in 1975-79 from the central population register of Finland (16). Data collection and analysis were approved by the ethics committee of the Department of Public Health of University of Helsinki and the IRB of Indiana University. 
The twins and their parents were sent baseline self-report questionnaires when the twins were 16 y (wave 1). Follow-up questionnaires were mailed to the twins when they were $17 \mathrm{y}$ (wave 2), $18 \mathrm{y}$ (wave 3), 22-27 y (mean $24 \mathrm{y}$, wave 4), and finally 31-37 y (mean $34 \mathrm{y}$, wave 5). The cohort and waves of data collection have been previously described in detail $(17,18)$. The analyses in the present study were restricted to individuals who participated in wave 4 (2,825 women and 2,423 men), when features of BED were assessed. Of them, 74\% participated in wave 5, and 94\% had at least one valid measure of BMI in adolescence.

\section{ASSESSMENT OF BMI AND FEATURES OF BED}

We calculated BMI from self-reported height and weight at each wave: age 16 through $34 \mathrm{y}$. Self-reported BMI correlated closely with measured BMI in a subsample of this cohort (19). The wave 4 questionnaire included three subscales of the Eating Disorder Inventory-2 (EDI): Bulimia, Drive for Thinness, and Body Dissatisfaction. Here we focus on seven items similar to the defining features of BED: six items from the Bulimia subscale: 'I eat when I'm upset', 'I stuff myself with food', 'I have gone on eating binges where I have felt that I could not stop', 'I think about bingeing (overeating)', 'I eat moderately in front of others and stuff myself when they're gone', 'I eat or drink in secrecy' and one item from the Drive for Thinness subscale: 'I feel extremely guilty after overeating'. Subjects were defined as positive for each item if they reported it sometimes, often, usually, or always, and negative if their answer was 'rarely' or 'never'. Finally, subjects were grouped according to how many features they reported. The resulting sum score had seven categories ranging from 'no features' to 'six or seven features' (9).

\section{STATISTICAL ANALYSES}

We used a multilevel growth curve modeling approach to estimate how the number of BED features at age 24 was associated with BMI trajectories over all five waves: age 16 (wave 1) through 34 years (wave 5). Specifically, we used mixed-effects linear regression fit by maximum likelihood estimation, with random intercepts and an unstructured covariance structure. The data were treated as irregularly spaced, accounting for the subjects' actual age 
at each wave. We also tested for interaction of the number of BED features with age. To account for correlation within twin pairs, we used robust variance estimation for clustered data (20). We conducted all analyses separately for women and men using Stata 13.1.

\section{RESULTS}

\section{BMI AT AGE 16}

The number of features of BED reported at age 24 was significantly associated with BMI at baseline (age 16) in both sexes. Mean BMI according to number of features is presented in Table 1. The clustering of six or seven features of BED was more common among women $(n=108,3.9 \%)$ than men $(n=6,0.3 \%)$. Of these individuals, $15 \%$ of women and $33 \%$ of men were already overweight or obese $(\mathrm{BMI}>25)$ at age 16 , as compared to $3 \%$ of those reporting no features (Table 1).

\section{FEATURES OF BED AND WEIGHT TRAJECTORIES}

The number of features of BED was associated with BMI trajectories from age 16 to 34 (Figure 1, Supplementary Table). The more BED features the subjects reported, the higher was their BMI through all fives waves. This was true both for women $(\beta=0.34, p<0.001)$ and men $(\beta=0.24, p<0.001)$. A significant interaction between the total number of BED features and age in both women $(\beta=0.018, p<0.001)$ and men $(\beta=0.030, p<0.001)$ indicated that the BMI trajectories of those endorsing more BED features were not only consistently higher, but also steeper. At the end of follow-up (age 34), $24 \%$ of the women and $60 \%$ of the men reporting 6 or 7 features were obese, as compared to $6 \%$ of women and $7 \%$ of men reporting no features.

To test the relative impact of clinical vs. subclinical BED features, we reran the analyses after excluding 16 women fulfilling diagnostic criteria for DSM-5 BED (6). The results remained virtually unchanged $(\beta=0.33, \mathrm{p}<0.001)$, suggesting that the subclinical "bulk of the iceberg" accounted for most of the association with BMI on the population level. 


\section{DISCUSSION}

Like an iceberg, the bulk of a health problem in a population may be hidden from view (1). Clinical BED is relatively rare (3-7) but its related features, both behaviors and cognitions, are common (9). We investigated whether such features of BED measured at mean age 24 were associated with weight development in adolescence and early adulthood. We found that the number of features of BED at age 24 was significantly associated with BMI at each wave from age 16 years onwards. Those reporting a higher number of BED features also continued to gain more weight throughout almost 20 years of follow-up.

The observation that disordered eating is associated with long-term weight gain is supported by several previous studies $(10-12,21)$. To our knowledge, our study is the first to systematically quantify how clustering of subclinical features of BED relates to weight development. The more BED-related cognitions and behaviors participants reported, the higher and steeper their weight trajectories were over time. Even subjects reporting just one or a few BED features gained more weight than those reporting none. It thus appears that these features form the bulk of the iceberg that may have significant public health consequences.

Adolescence and young adulthood are critical periods for weight gain $(22,23)$. In our sample, it is apparent that the diverging of weight trajectories had started before age 16, perhaps already in childhood (24). Previous studies have shown that loss of control eating is present already in childhood $(12,25)$, but in our setting we cannot establish whether weight gain was preceded by disordered eating or vice versa. Weight gain in childhood or adolescence may also have preceded the features of BED, as being heavier than one's peers may trigger weight loss attempts and loss of control $(26,27)$. More research is needed on the onset and timing of these behaviors.

\section{Limitations}

Our study is subject to a number of limitations. First, the BED features were only assessed once, at age 24 , and we therefore lack information on how these behaviors and cognitions 
evolved in adolescence. Second, all study variables were self-reported via questionnaire, which may cause reporting bias, particularly underreporting of weight and overreporting of height, potentially leading to underestimation of BMI. However, self-reported BMI correlated closely with measured BMI in a subsample of this cohort (19). Third, missing data due to attrition could affect the results. Yet, our response rates were high throughout follow-up (17, 18), the statistical methods used are robust to missing data, and we found no evidence of selective attrition in respect to BED features between Waves 4 and 5 (9).

\section{Conclusions}

The hidden bulk of the iceberg of BED features is associated with unfavorable weight development throughout adolescence and into the fourth decade of life. Although subclinical eating-disorder features are often overlooked, they are common in the population and are potential intervention targets for obesity prevention. Interventions reducing binge eating have shown effectiveness for weight loss and obesity prevention in youth $(28,29)$. Regulation of eating is also where the neurobiology of obesity points to (30). We posit that obesity prevention programs should target disordered eating alongside with traditional risk factors such as sedentary lifestyle and energy-dense diets. Given that the unfavorable weight development starts early, interventions should be timed accordingly.

\section{ACKNOWLEDGEMENTS}

The data collection and analysis was supported by the Academy of Finland (grants 141054, 265240, 263278 and 264146 to JK). LM received funding from the Finnish Medical Foundation, the Biomedicum Helsinki Foundation, and the Finnish Cultural Foundation. 


\section{REFERENCES}

1. Last JM, Adelaide DP. The iceberg: 'completing the clinical picture' in general practice. 1963. Int J Epidemiol. 2013;42(6):1608-13.

2. Porta M. A Dictionary of Epidemiology. 6th ed: Oxford University Press; 2014. 3. Hudson JI, Hiripi E, Pope HG, Jr., Kessler RC. The prevalence and correlates of eating disorders in the National Comorbidity Survey Replication. Biological psychiatry. 2007;61(3):348-58.

4. Preti A, Girolamo G, Vilagut G, Alonso J, Graaf R, Bruffaerts R, et al. The epidemiology of eating disorders in six European countries: results of the ESEMeD-WMH project. Journal of psychiatric research. 2009;43(14):1125-32.

5. Kessler RC, Berglund PA, Chiu WT, Deitz AC, Hudson JI, Shahly V, et al. The prevalence and correlates of binge eating disorder in the World Health Organization World Mental Health Surveys. Biological psychiatry. 2013;73(9):904-14.

6. Mustelin L, Raevuori A, Hoek HW, Kaprio J, Keski-Rahkonen A. Incidence and weight trajectories of binge eating disorder among young women in the community. The International journal of eating disorders. 2015;48(8):1106-12.

7. Smink FR, van Hoeken D, Oldehinkel AJ, Hoek HW. Prevalence and severity of DSM-5 eating disorders in a community cohort of adolescents. The International journal of eating disorders. 2014;47(6):610-9.

8. de Zwaan M. Binge eating disorder and obesity. International journal of obesity and related metabolic disorders : journal of the International Association for the Study of Obesity. 2001;25 Suppl 1:S51-5.

9. Mustelin L, Bulik CM, Kaprio J, Keski-Rahkonen A. Prevalence and correlates of binge eating disorder related features in the community. Appetite. 2017;109:165-71.

10. Tanofsky-Kraff M, Yanovski SZ, Schvey NA, Olsen CH, Gustafson J, Yanovski JA. A prospective study of loss of control eating for body weight gain in children at high risk for adult obesity. The International journal of eating disorders. 2009;42(1):26-30.

11. Sonneville KR, Horton NJ, Micali N, Crosby RD, Swanson SA, Solmi F, et al. Longitudinal associations between binge eating and overeating and adverse outcomes among adolescents and young adults: does loss of control matter? JAMA pediatrics.

2013;167(2):149-55.

12. Tanofsky-Kraff M, Cohen ML, Yanovski SZ, Cox C, Theim KR, Keil M, et al. A prospective study of psychological predictors of body fat gain among children at high risk for adult obesity. Pediatrics. 2006;117(4):1203-9.

13. Goldschmidt AB, Wall MM, Loth KA, Bucchianeri MM, Neumark-Sztainer D. The course of binge eating from adolescence to young adulthood. Health psychology : official journal of the Division of Health Psychology, American Psychological Association. 2014;33(5):457-60.

14. Ackard DM, Neumark-Sztainer D, Story M, Perry C. Overeating among adolescents: prevalence and associations with weight-related characteristics and psychological health. Pediatrics. 2003;111(1):67-74.

15. Neumark-Sztainer D, Wall M, Larson NI, Eisenberg ME, Loth K. Dieting and disordered eating behaviors from adolescence to young adulthood: findings from a 10-year longitudinal study. Journal of the American Dietetic Association. 2011;111(7):1004-11. 16. Kaprio J, Pulkkinen L, Rose RJ. Genetic and environmental factors in health-related behaviors: studies on Finnish twins and twin families. Twin research : the official journal of the International Society for Twin Studies. 2002;5(5):366-71.

17. Kaprio J. The Finnish Twin Cohort Study: an update. Twin research and human genetics : the official journal of the International Society for Twin Studies. 2013;16(1):157-62. 18. Kaprio J. Twin studies in Finland 2006. Twin research and human genetics : the official journal of the International Society for Twin Studies. 2006;9(6):772-7. 
19. Mustelin L, Silventoinen K, Pietilainen K, Rissanen A, Kaprio J. Physical activity reduces the influence of genetic effects on BMI and waist circumference: a study in young adult twins. International journal of obesity (2005). 2009;33(1):29-36.

20. Williams RL. A note on robust variance estimation for cluster-correlated data. Biometrics. 2000;56(2):645-6.

21. Neumark-Sztainer D, Wall M, Guo J, Story M, Haines J, Eisenberg M. Obesity, disordered eating, and eating disorders in a longitudinal study of adolescents: how do dieters fare 5 years later? Journal of the American Dietetic Association. 2006;106(4):559-68.

22. Pietilainen KH, Rissanen A, Laamanen M, Lindholm AK, Markkula H, Yki-Jarvinen $\mathrm{H}$, et al. Growth patterns in young adult monozygotic twin pairs discordant and concordant for obesity. Twin research : the official journal of the International Society for Twin Studies. 2004;7(5):421-9.

23. Kimm SY, Barton BA, Obarzanek E, McMahon RP, Kronsberg SS, Waclawiw MA, et al. Obesity development during adolescence in a biracial cohort: the NHLBI Growth and Health Study. Pediatrics. 2002;110(5):e54.

24. Dietz WH. Critical periods in childhood for the development of obesity. Am J Clin Nutr. 1994;59(5):955-9.

25. Tanofsky-Kraff M, Goossens L, Eddy KT, Ringham R, Goldschmidt A, Yanovski SZ, et al. A multisite investigation of binge eating behaviors in children and adolescents. $\mathrm{J}$

Consult Clin Psychol. 2007;75(6):901-13.

26. Tanofsky-Kraff M, Faden D, Yanovski SZ, Wilfley DE, Yanovski JA. The perceived onset of dieting and loss of control eating behaviors in overweight children. Int J Eat Disord. 2005;38(2):112-22.

27. Reas DL, Grilo CM. Timing and sequence of the onset of overweight, dieting, and binge eating in overweight patients with binge eating disorder. The International journal of eating disorders. 2007;40(2):165-70.

28. Jones M, Luce KH, Osborne MI, Taylor K, Cunning D, Doyle AC, et al. Randomized, controlled trial of an internet-facilitated intervention for reducing binge eating and overweight in adolescents. Pediatrics. 2008;121(3):453-62.

29. Tanofsky-Kraff M, Shomaker LB, Wilfley DE, Young JF, Sbrocco T, Stephens M, et al. Targeted prevention of excess weight gain and eating disorders in high-risk adolescent girls: a randomized controlled trial. The American Journal of Clinical Nutrition. 2014;100(4):1010-8.

30. Locke AE, Kahali B, Berndt SI, Justice AE, Pers TH, Day FR, et al. Genetic studies of body mass index yield new insights for obesity biology. Nature. 2015;518(7538):197-206. 
Figure legend:

Figure 1. Weight trajectories (mean BMI) from adolescence to adulthood of women and men reporting different numbers of features of binge eating disorder at mean age 24 . 
Table 1. BMI and proportion of overweight and obese subjects at age 16 according to total number of BED features at age 24 .

\begin{tabular}{|c|c|c|c|c|c|c|}
\hline & \multicolumn{6}{|c|}{ Women $\left(\mathrm{N}=2550^{*}\right)$} \\
\hline & $\mathrm{N}(\%)$ & $\begin{array}{c}\text { Mean } \\
\text { BMI }\end{array}$ & $\begin{array}{c}95 \% \\
\text { confiden } \\
\text { ce } \\
\text { interval } \\
\end{array}$ & $\begin{array}{c}\text { Linear } \\
\text { regression }\end{array}$ & $\begin{array}{l}\text { Overweight } \\
\text { or obese }(\%)\end{array}$ & $\begin{array}{c}\text { Obese } \\
(\%)\end{array}$ \\
\hline 0 & $835(33)$ & 19.8 & $19.6,19.9$ & & 3.1 & 0.4 \\
\hline 1 & $672(26)$ & 20.0 & $19.8,20.2$ & & 2.0 & 0.4 \\
\hline 2 & 445 (17) & 20.4 & $20.2,20.7$ & & 3.6 & 0.7 \\
\hline 3 & $266(10)$ & 20.9 & $20.5,21.2$ & & 5.6 & 0.8 \\
\hline 4 & $150(5.9)$ & 20.9 & $20.4,21.3$ & & 6.0 & 0.7 \\
\hline 5 & $90(3.5)$ & 21.2 & $20.6,21.8$ & & 11 & 0.0 \\
\hline \multirow[t]{3}{*}{$6-7$} & $92(3.6)$ & 21.9 & $21.3,22.6$ & & 15 & 4.3 \\
\hline & & \multicolumn{5}{|c|}{$\begin{array}{l}\beta=0.33, \\
p<0.001\end{array}$} \\
\hline & & \multicolumn{5}{|c|}{$\operatorname{Men}\left(\mathrm{N}=2105^{*}\right)$} \\
\hline 0 & $920(44)$ & 20.3 & $20.1,20.4$ & & 3.2 & 0.3 \\
\hline 1 & $847(40)$ & 20.4 & $20.2,20.5$ & & 3.4 & 0.2 \\
\hline 2 & $214(10)$ & 20.7 & $20.3,21.0$ & & 5.1 & 0.5 \\
\hline 3 & $73(3.5)$ & 20.8 & $20.2,21.3$ & & 5.5 & 0.0 \\
\hline 4 & $28(1.3)$ & 20.7 & $20.1,21.3$ & & 0.0 & 0.0 \\
\hline 5 & $17(0.81)$ & 21.8 & $20.6,23.0$ & & 12 & 0.0 \\
\hline \multirow[t]{2}{*}{$6-7$} & $6(0.29)$ & 21.7 & $17.6,25.9$ & & 33 & 0.0 \\
\hline & \multicolumn{6}{|c|}{$\begin{array}{l}\beta=0.19 \\
p=0.002\end{array}$} \\
\hline
\end{tabular}

*Number of subjects with data available both for features of BED at age 24 and BMI at age 16. 
Supplementary Table. Mixed effects model of the longitudinal association between binge-eating summary score and BMI trajectories through age 16 to 34 .

Women

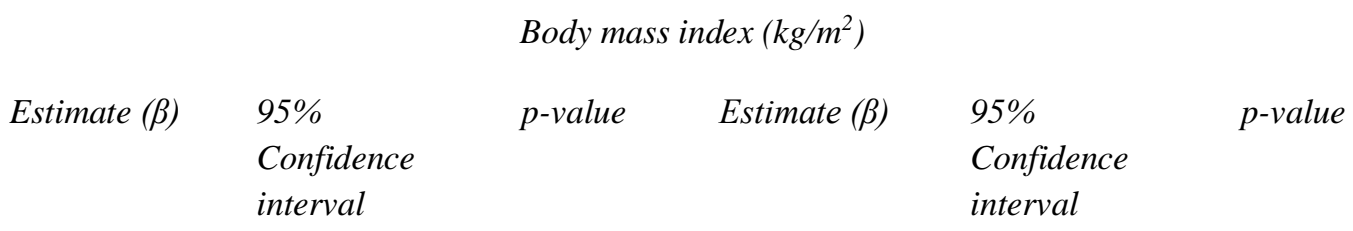

\section{Fixed effect}

Binge-eating summary score

$$
0.34
$$

$0.28 ; 0.41$

$<0.001$

0.24

$0.17 ; 0.20$

$<0.001$

0.28

$0.01 ; 0.02$

$<0.001$

0.030

$19.7 ; 19.9$

$<0.001$

20.6

$20.5 ; 20.7$

$0.13 ; 0.36$

$<0.001$

$0.27 ; 0.30$

$<0.001$

Bin

Intercept

19.8

\section{Random effect}

Level 2 variance (between

individuals)

Age

Intercept

Covariance (Age, Intercept)

0.053

$0.015 ; 0.090$

0.029

$0.014 ; 0.046$

$<0.001$

Level 1 variance (within

individuals)

Residual

1.31

$1.19 ; 1.43$

1.62 